\title{
Direito Fundamental à Educação e Home Schooling a Educação Doméstica na Lei de Diretrizes e Bases da Educação Nacional
}

\section{Juliana Cristine Diniz Campos}

Mestre em Direito Constitucional pela Universidade Federal do Ceará (UFG). Doutoranda em Direito do Estado pela Universidade de São Paulo (USP). julianacdcampos@gmail.com

Sumário: Introdução. I. A educação como vir-a-ser: complexidade e socialização. II. A obrigatoriedade do ensino básico e o dever de matrícula. III. O paradigma jurisprudencial. Conclusões. Referências.

Resumo: O artigo analisa a educação doméstica no Brasil, sob a perspectiva jurídica. Busca investigar se é possível ao responsável legal optar por tal modalidade educativa, em que medida e em que condições, a partir da análise do direito positivo, em seu nível constitucional e infraconstitucional, e da pragmática jurisprudencial aplicável à questão.

Palavras-chave: Educação Doméstica. Direitos Fundamentais.

\section{INTRODUÇÃO}

$\mathrm{O}$ direito à educação - entendida como processo contínuo de aprendizagem e desenvolvimento voltado à conquista da autonomia do indivíduo - é qualificado como direito fundamental indisponível, notadamente no que tange ao ensino básico dirigido a crianças e adolescentes, dada a instituição do regime constitucional da proteção integral (MARQUES, 2004:46). Isso implica dizer que os responsáveis legais, tendo o dever de zelar pelo bem-estar do tutelado, devem, obrigatoriamente, promover a matrícula deste na rede pública ou privada de ensino, a fim de que possa acompanhar o processo educativo formal, sob pena de intervenção do Ministério Público.

Em um país de graves desigualdades sociais, o nível de efetividade do direito à educação parece estar longe de alcançar um patamar ótimo, seja em virtude da falta 
de acesso à rede escolar, seja por conta da má qualidade do ensino de um modo geral. Diante da insuficiência estrutural do estado para atender à demanda por um ensino de qualidade e por prestações educativas diferenciadas para alunos especiais, surge, muitas vezes, a pretensão de educar a criança e o adolescente no ambiente familiar, também chamada de educação doméstica (cujo equivalente em inglês, de ampla utilização na bibliografia brasileira, é o home schooling). Questiona-se se a obrigatoriedade da matrícula da criança no ensino formal não constituiria ofensa ao princípio da liberdade de educar e ao direito dos pais de escolherem a educação adequada para seus filhos.

Neste trabalho, pretende-se investigar, sob o prisma analítico, em face do direito positivo aplicável à educação no Brasil, se é possível à família optar pela educação doméstica, considerando a indisponibilidade e as peculiaridades normativas do direito à educação. A partir de um prévio estudo da legislação, passaremos à análise de um caso concreto paradigmático, enfrentado pelo STJ no mandado de segurança 2001/00228437, cuja decisão considerou aplicável o parecer do Conselho Nacional de Educação no 34/2000, pela impossibilidade de se privar a criança do ambiente escolar formal.

A pesquisa, entretanto, não se pretende limitar ao aspecto estritamente positivo da questão, na medida em que as normas relativas aos direitos fundamentais se configuram por sua abertura semântica, que exigem do intérprete, para além de uma técnica de operação do sistema, uma disposição argumentativa a enfrentar questões que, muitas vezes, antes de jurídicas, são estritamente filosóficas: o que é educação? Quais são os seus fins? O que se considera liberdade? Qual o papel do estado nesse processo? Entre outras. Nesse sentido, é necessário abordar, neste trabalho, o sentido da educação em sua perspectiva processual (o educar como vir-a-ser), e da relevância da dicotomia indivíduo/sociedade (simbolizada no binômio aluno/escola) para o êxito do empreendimento educacional.

O direito fundamental de índole prestacional admite níveis de efetividade e modos de adimplemento plurais. Nesse sentido, é possível afirmar que, conforme diferenciadas as circunstâncias fáticas que envolvem o titular e a prestação exigida, pode-se encontrar soluções diferentes, sem que a diversidade implique insegurança ou ofensa ao mínimo ético relativo ao direito.

\section{AEDUCAÇÃO COMO VIR-A-SER: COMPLEXIDADE E SOCIALIZAÇÃO}

$\mathrm{O}$ ato de educar é, antes de tudo, um meio de adaptação do indivíduo ao meio social em que está inserido: através da transmissão de um modo de existir típico, o eu pode comunicar-se e integrar-se ao ambiente social constituído de símbolos, práticas e linguagem próprios. Esse processo, caracterizado pela sua complexidade e difusão, inicia-se com o nascimento e é levado a cabo por inúmeros atores sociais, para além 
do núcleo familiar. Implica dizer que o homem torna-se "mais humano (histórico) à medida que desenvolve suas potencialidades, que à sua natureza vai acrescentando cultura, pela apropriação de conhecimentos, informações, valores, crenças, habilidades artísticas etc" (PARO, 2008:25). Brandão esclarece o caráter difuso do ato educativo:

\begin{abstract}
A educação pode existir livre e, entre todos, pode ser uma das maneiras que as pessoas criam para tornar comum, como saber, como ideia, como crença, aquilo que é comunitário como bem, como trabalho ou como vida. Ela pode existir imposta por um sistema centralizado de poder, que usa o saber e o controle sobre o saber como armas que reforçam a desigualdade entre os homens, na divisão dos bens, do trabalho, do direito e dos símbolos.
\end{abstract}

A educação é, como outras, uma fração do modo de vida dos grupos sociais que a criam e recriam, entre tantas outras invenções de sua cultura, em sua sociedade (2007:10).

A partir dessa perspectiva, pode-se dizer que se educar é, antes de apreender um certo conteúdo, socializar-se, interagindo e produzindo cultura pela transformação simbólica da natureza. Por essa razão, é preciso esclarecer a confusão habitual entre os vocábulos educação - relativa a esse processo mencionado - e ensino, enquanto práxis cientificamente orientada ao desenvolvimento intelectual do indivíduo, operada, regra geral, no ambiente formal escolar.

$\mathrm{O}$ artigo $1^{\circ}$ da Lei de Diretrizes e Bases da Educação Nacional estabelece uma distinção pertinente. Segundo o dispositivo, "a educação abrange os processos formativos que se desenvolvem na vida familiar, na convivência humana, no trabalho, nas instituições de ensino e pesquisa, nos movimentos sociais e organizações da sociedade civil e nas manifestações culturais, ressaltando-se que esta lei disciplina a educação escolar, que se desenvolve, predominantemente, por meio do ensino, em instituições próprias" $\left(\S 1^{\circ}\right)$.

Nesse contexto, é preciso reconhecer que, muito embora a família tenha uma participação importantíssima no processo educativo como um todo, a orientação racional do ensino assume, desde a escolarização, o papel de favorecer a igualdade entre os educandos, seu desenvolvimento como grupo. Cury esclarece o processo de distribuição social dos conhecimentos, que resulta em um processo educativo difuso e plural:

Ora, a grande pluralidade institucional no mundo social implica também a distribuição social dos conhecimentos dentro das sociedades modernas. Assim, há que se reconhecer o papel original da família na aquisição de padrões comuns e de um quadro social de referências relativo a um sistema social. Nesse processo as crianças vão aprendendo a cumprir papéis e assumir valores básicos de referência a esse sistema, dando-se tanto uma ação objetiva da sociedade para a pessoa quanto uma ação subjetiva de recepção por parte da mesma. Nesse sentido, a família é um agente original e imediato de socialização da criança. A socialização, na perspectiva interacionista de Mollo-Bouvier (2005) explicita que a integração do indivíduo na vida coletiva é também conhecimento de si e conhecimento do outro, construção de si e construção do outro (CURY, 2006:670). 
A partir dessa perspectiva, observa-se, de antemão, a necessidade de socialização para o êxito do empreendimento educacional. $\mathrm{O}$ eu que se forma a partir do contato com o outro, portanto. A educação é compreendida como um processo complexo de inclusão, a partir da interação dialética entre identificação/diferenciação do indivíduo, acentuado no período de escolarização do ensino.

A socialização é classificada por Berger em primária e secundária: no primeiro caso, refere-se à acepção geral e vulgar de educação, relativa à transmissão da forma de vida ao indivíduo pela família e demais atores sociais; no segundo, tem-se o aprofundamento dos níveis de interação do indivíduo pela complexidade crescente de aspectos como distinção dos grupos etários, participação política, inserção profissional etc (BERGER).

O ambiente escolar é constituído, portanto, como locus de socialização secundária típico, onde o indivíduo é confrontado com a diferença e a pluralidade, diversificando-se o aparato cultural já transmitido pela família.

A educação escolarizada é compreendida, portanto, como uma prática refletida, orientada conscientemente a um fim, que é a emancipação do indivíduo para a prática do trabalho e para a vida cidadã. Os fins da educação são expressos no artigo 205 da Constituição Federal, que limita o campo semântico de abrangência da norma, ao mesmo tempo em que orienta a aplicação do instituto. Nesse sentido, uma educação que não favoreça uma articulação entre trabalho e cidadania mostra-se contrária à constituição, dada sua inadequação em relação ao projeto político nacional (GURY).

A restrição da educação ao ambiente doméstico provoca, assim, relativamente ao aspecto teleológico da norma constitucional, uma tensão dificil de ser superada por uma interpretação adequada constitucionalmente, na medida em que a inclusão do indivíduo é contraposta à pretensão familiar de concentrar sua socialização ao aspecto primário.

\section{AOBRIGATORIEDADE DO ENSINO BÁSICO E O DEVER DE MATRÍCULA}

Em análise aos dispositivos constitucionais e infraconstitucionais aplicáveis à questão, é possível afirmar que, do ponto de vista positivo, a interpretação mais coerente é pelo dever dos responsáveis pela matrícula do aluno na rede regular de ensino, seja privada ou pública. Nesse sentido, não haveria uma prerrogativa dos pais em optar pela educação doméstica, revelando-se a omissão em matricular um ato de negligência passível de controle pelo Ministério Público.

Isso porque, conforme o artigo 208, I, da Constituição Federal, o ensino é obrigatório dos quatro aos dezessete anos, abrangendo a educação infantil, o ensino fundamental e o ensino médio. A alteração é recente, incluída pela emenda constitucional n 59 de 2009, e representa um avanço em termos de garantia da educação. Antes da 
emenda referida, a obrigatoriedade do ensino se restringia ao ensino fundamental, havendo quem sustentasse a inexistência de direito subjetivo da criança à educação infantil em creches, por exemplo.

Com a expressa modificação, o termo obrigatoriedade passa a abranger todo o ensino básico, tal como indicado pelo artigo 21, I da LDB. A obrigação refere-se, portanto, ao ato de promover a inclusão do aluno, pela matrícula, na rede de ensino, a fim de que possa ter suas possibilidades desenvolvidas. É dizer que o direito à educação da criança e do adolescente não é disponível aos pais, que têm o dever de zelar pelo acompanhamento pedagógico em rede oficial, sob pena de responsabilização. Esclarece Liberati:

A obrigatoriedade do ensino fundamental desdobra-se em dois momentos: do Poder Público, que deve oferecer (obrigatoriamente) o serviço essencial e básico da educação; e dos pais, que devem (obrigatoriamente) matricular seus filhos. Temos, portanto, dois atores responsáveis pela garantia do direito à educação, e termos a criança e o adolescente, que são protagonistas de seu direito ao acesso, à permanência e ao ensino de qualidade no ensino fundamental (LIBERATI, 2004:224)․

Essa é a orientação do artigo 55 do Estatuto da Criança e do Adolescente, ao indicar que os pais ou responsável têm a obrigação de matricular seus fihos ou pupilos na rede regular de ensino, sob pena de aplicação de uma das medidas previstas no artigo 129 da mesma lei.

A dúvida surge quanto a um possível conflito entre o direito à educação na rede oficial de ensino e a liberdade de educar e aprender prevista na própria Constituição, em seu artigo 206, II, tendo em vista a previsão do artigo 24, II, alínea "c" da Lei de Diretrizes e Bases da Educação Nacional. Segundo o dispositivo, permite-se que "a classificação em qualquer série ou etapa, exceto a primeira do ensino fundamental seja feita independentemente de escolarização anterior, mediante avaliação feita pela escola, que defina seu grau de desenvolvimento e experiência do candidato e permita sua inscrição na série ou etapa adequada, conforme regulamentação do respectivo sistema de ensino."

Desse modo, haveria, em tese, "a liberdade" de escolha do modo de educação da criança e do adolescente, inclusive quanto à possibilidade da educação doméstica, considerando a possibilidade de classificação posterior em série mediante avaliação da escola.

O entendimento, entretanto, não é acolhido pelo Conselho Nacional de Educação, que, incitado a se manifestar sobre a possibilidade de uma dada família educar os filhos no ambiente doméstico, através do parecer n 34 de 2000, salientou:

\footnotetext{
A leitura do texto deve levar em consideração a mudança operada pela emenda constitucional no 59 de 2009, que alterou a Constituição para o fim de ampliar a educação obrigatória a todo o ensino básico, e não apenas ao ensino fundamental.
} 
Verifica-se, assim, que a Constituição Federal aponta nitidamente para a obrigatoriedade da presença do aluno na escola, em especial na faixa de escolarização obrigatória (7 a 14 anos), instituindo para o Poder Público a obrigação de recensear, fazer a chamada escolar e zelar para que os pais se responsabilizem pela "freqüência à escola".

O entendimento construído pelo órgão executivo foi discutido judicialmente pela via do mandado de segurança, considerando a inconformação dos pais ante a impossibilidade de prosseguir na educação doméstica.

\section{PARADIGMAJURISPRUDENCIAL}

O mandado de segurança 2001/0022843-7, decidido pelo STJ em última instância, representa um paradigma jurisprudencial interessante sobre a matéria, salientando a perspectiva constitucional da interpretação do direito à educação, como direito subjetivo indisponível, de responsabilidade múltipla. O entendimento tende a ampliar o sentido de educação pela previsão de seus fins, salientando o caráter progressivo do processo educativo, enquanto devir.

No caso em referência, os pais de três crianças em idade escolar pleiteavam a desconsideração do parecer $n^{\circ} 34$ de 2000, a fim de que pudessem persistir no homeschooling. A decisão reitera a importância da socialização no processo educativo, esclarecendo que:

os filhos não são dos pais, como pensam os autores. São pessoas com direitos e deveres, cujas personalidades se devem forjar desde a adolescência em meio a iguais, no convívio social formador da cidadania. Aos pais cabem, sim, as obrigações de manter e educar os folhos consoante a Constituição e as leis do País, asseguradoras do direito do menor à escola (art. $5^{\circ}$ e 53, I, da Lei n ${ }^{\circ}$ 8.096/90) e impositivas de providências e sanções voltadas à educação dos jovens (excerto do voto do relator).

A decisão, ao entender sem aparo legal a pretensão dos pais, cuidou de estabelecer um paradigma contrário à adoção da educação doméstica no Brasil, em virtude da pluralidade do processo educativo e da responsabilidade social em seu desenvolvimento.

\section{CONCLUSÕES}

As questões enfrentadas neste trabalho demonstram a existência de um senso comum sobre educação que a identifica como mecanismo institucional de transmissão

${ }_{1}$ O parecer mencionado encontra-se no anexo deste artigo, na íntegra. 
de conhecimentos. A partir dessa perspectiva, o êxito do empreendimento educacional é avaliado pela capacidade da criança em absorver dados, o que levou Freire a identificar o modelo como espécie de educação bancária, cuja tarefa seria 'encher' os educandos dos conteúdos de sua narração (FREIRE, 2005:65).

No mandado de segurança mencionado, um dos argumentos utilizados para sustentar o direito de educar os filhos no ambiente doméstico foi o resultado das avaliações das crianças, superiores, em nota, aos de alunos na mesma faixa etária e nível de educação, dada a impertinência em se falar em "escolarização" no caso. Essa visão desconsidera que o processo educativo tem como fim primordial transformar o indivíduo em ser humano, conquistar sua cidadania, seu comprometimento com o projeto político comum.

Por essa razão, inexistiria uma "prerrogativa constitucional" dos pais em optar pela exclusão de seus filhos da ambiência escolar, tendo em vista a insuficiência do lar no quesito socialização secundária, ou seja, no processo de inclusão social do sujeito, a partir da percepção da diferença. Isso porque o sentido constitucional de educação é explicitado pelo teor do artigo 205, que salienta a responsabilidade do estado e da família na formação para cidadania e para o trabalho.

\section{REFERÊNCIAS}

BERGER, P. L. A Construção Social da Realidade Petrópolis: Vozes, 1973.

BRANDÃO, G.R. O que é Educação. São Paulo: Brasiliense, 2007.

CURY, Carlos Roberto Jamil. Educação Escolar e Educação no Lar: E spaços de uma Polêmica. In: Educ. Soc., Campinas, vol. 27, n. 96 - Especial, p. 667-688, out. 2006. Disponível em: www.cedes.unicamp.br.

FREIRE, P. Pedagogia do Oprimido, 47 Ed. Rio de Janeiro: Paz e Terra, 2005.

LIBERATI, W. D. Conteúdo M aterial do D ireito à E ducação E scolar. In:

LIBERATI, W. D. (org.). Direito à Educação: Uma Questão de Justiça. São Paulo: Malheiros, 2004.

MARQUES, M. T. S. Sistema de Garantia de Direitos da Infância e da Juventude. In: LIBERATI, W. D. (org.). Direito à Educação: Uma Questão de J ustiça. São Paulo: Malheiros, 2004.

PARO, V. H. Educação como Exercício do Poder: Crítica ao Senso Comum em Educação. São Paulo: Cortez, 2008. 


\section{HOME SCHOOLING AND THE BRAZILIAN}

\section{EDUCATION LAW}

Abstract: This paper analyses the home schooling in Brazil. It proposes to investigate if it is possible for parents to home school their children and, if so, in which conditions and scopes, according to the Brazilian Constitution, ordinary laws and national jurisprudence.

Keywords: Home Schooling. Civil Rights. 


\section{MINISTÉRIO DA EDUCAÇÃO CONSELHO NACIONAL DE EDUCAÇÃO}

\begin{tabular}{|c|c|c|}
\hline \multicolumn{3}{|c|}{ INTERESSADO: Conselho Estadual de Educação de Goiás } \\
\hline \multicolumn{3}{|c|}{ ASSUNTO: Validação de ensino ministrado no lar } \\
\hline \multicolumn{3}{|c|}{ RELATOR(A): Ulysses de Oliveira Panisset } \\
\hline \multicolumn{3}{|c|}{ PROCESSO(S) N. ${ }^{\circ}$ (S): $23001.000301 / 2000-37$} \\
\hline $\begin{array}{l}\text { PARECER N. }{ }^{0}: \\
\text { CEB 034/2000 }\end{array}$ & $\begin{array}{c}\text { COLEGIADO: } \\
\text { CEB }\end{array}$ & $\begin{array}{r}\text { APROVADO EM: } \\
04 / 12 / 2000\end{array}$ \\
\hline
\end{tabular}

\section{I - RELATÓRIO}

\section{Histórico}

A Senhora Diretora do Conselho Estadual de Educação de Goiás, cumprindo despacho da Senhora Conselheira Rosa Nina Mathias de Azevedo, relatora de processo em tramitação naquele colegiado, endereçou pedido de manifestação deste Conselho sobre a matéria contida no mesmo, por entender que demanda pronunciamento de abrangência nacional.

Trata-se do requerimento de casal constituído pelo Sr. Carlos Alberto Carvalho Vilhena Coelho e pela Sra. Márcia Marques de Oliveira de Vilhena Coelho, que pleiteiam o direito de educar os filhos em casa, buscando uma escola apenas para submetê-los a avaliações periódicas quanto ao nível de preparo que atinjam.

Por decisão do senhor presidente da Câmara de Educação Básica, fui constituído relator da matéria.

O pleito do casal mencionado está claramente explicitado no documento com o qual suas idéias foram submetidas ao egrégio Conselho Estadual de Educação de Goiás. Ali vem dito, verbis: 
PARECER CNE/CEB 34/2000 - HOMOLOGADO

Despacho do Ministro em 15/12/2000, publicado no Diário Oficial da União de 18/12/2000, Seção 1, p. 30.

Mais adiante, admitindo haverem ocorrido sensíveis avanços legislativos no país, "a família concluiu que chegou a hora de buscar o reconhecimento estadual dessa modalidade de educação".

Acrescentando,

"Foi então que a família, acreditando que já era tempo de materializar o histórico escolar que refletisse o grau de conhecimento científico adquirido pelos filhos, procurou conhecer as escolas de ensino fundamental atualmente existentes em Anápolis/GO, da rede pública e privada, e optou por aquela que, na sua opinião, apresentava uma proposta educacional exigente, preocupada com a formação integral do aluno e com a sua futura habilitação para enfrentar com sucesso o concurso vestibular: o Colégio Imaculada Conceição".

Segue-se a afirmação de que os filhos - na $5^{\mathrm{a}}$, na $4^{\mathrm{a}}$ e na $1^{\mathrm{a}}$ séries - se acham "Regularmente matriculados no presente ano letivo(...) estudando exclusivamente em casa, vale dizer, sem freqüentar as salas de aulas", tendo passado a ser "mensalmente avaliados pela citada escola, nos mesmos locais, dias e horas das avaliações dos demais alunos". A tudo, é adicionada a informação de que os resultados "tidos por obrigatórios, foram bastante satisfatórios".

Assim, em resumo, a intenção dos pais que firmam o expediente ora considerado é que lhes seja reconhecido o direito de educarem os filhos sem a obrigatoriedade de freqüência regular a qualquer escola.

\section{Mérito}

A educação de crianças e adolescentes no exclusivo recesso da família não é um assunto novo no mundo. Na verdade, tem sido objeto de estudos, de debates, não somente em esferas acadêmicas como até mesmo no terreno objetivo em certos países. Por exemplo, nos Estados Unidos já existe até uma entidade - "Senior Counsel of the Home School Legal Defense" - que propugna pelo direito dos pais, de mandarem, ou não, suas crianças à escola, de forma regular.

Em trinta e três anos de atuação, como membro do Conselho Estadual de Educação de Minas Gerais agora acrescidos de cinco anos como integrante do Conselho Nacional de Educação, nunca me deparara com essa questão no Brasil. O que ocorria era o oposto, ou seja, a grita de pais que reclamavam a falta de vagas para os filhos nas escolas públicas, para que lhes fosse garantido o direito dos mesmos ao ensino fundamental, etapa da educação básica que a Constituição Federal, impõe seja assegurada a todos. 


\section{PARECER CNE/CEB 34/2000 - HOMOLOGADO}

Despacho do Ministro em 15/12/2000, publicado no Diário Oficial da União de 18/12/2000, Seção 1, p. 30.

Busco refletir com a minha melhor atenção, sobre o inusitado tema.

Antes, não posso deixar sem um registro de apreciação o desvelo com que o casal que assina o documento ora considerado se dedica ao desafiador mas sublime compromisso de educar os quatro filhos já nascidos, além de se preparar para o mesmo trabalho em relação ao quinto, que está a caminho. como consta da exposição feita. A ambos, pois, a minha muito sincera homenagem e o meu respeito.

A despeito dessa grande admiração, incumbe-me, no exercício da responsabilidade a mim deferida, como relator, examinar a questão sob todos os seus múltiplos aspectos, de natureza pedagógica ou legal, ainda que de forma sintetizada, para que seja contida no parecer em curso.

Por certo, é oportuno lembrar, de início, o disposto no art. 90 da Lei n ${ }^{\circ} 9.394$, de 20 de dezembro de 1996, a nova Lei de Diretrizes e Bases da Educação Nacional, do seguinte teor:

"Art. 90 - As questões suscitadas na transição entre o regime anterior e o que se institui nesta Lei serão resolvidos pelo Conselho Nacional de Educação ou mediante delegação deste, pelos órgãos normativos dos sistemas de ensino, preservada a autonomia universitária".

É, pois, no cumprimento do artigo transcrito que serão buscados os dispositivos da LDB nos quais se apoiarão as conclusões desta manifestação.

Sem esquecer que a referida lei decorre, ela própria, de dispositivo constitucional que atribui competência à União, por seu Congresso Nacional, é claro, para legislar sobre "diretrizes e bases da educação nacional" (C.F., art. 22, inciso XXIV).

Também, para construir o embasamento destas reflexões, é conveniente transcrever o art. 227 da Constituição Federal, invocado na argumentação do distinto casal:

"Art. 227 - É dever da família, da sociedade e do Estado assegurar à criança e ao adolescente, com absoluta prioridade, o direito à vida, à saúde, à alimentação, à educação, ao lazer, à profissionalização, à cultura, à dignidade, ao respeito, à liberdade e à convivência familiar e comunitária, além de colocá-los a salvo de toda forma de negligência, discriminação, violência, crueldade e opressão."

Desde logo, seria de se ressaltar que o dever de que fala o art. 227 é "da família, da sociedade e do Estado". Em termos de entidades, trata-se, portanto, de uma tríplice e compartilhada responsabilidade. E é natural que assim seja, como uma obrigação cuja abrangência exige o empenho cooperativo de multivariados parceiros, a família, 
PARECER CNE/CEB 34/2000 - HOMOLOGADO

Despacho do Ministro em 15/12/2000, publicado no Diário Oficial da União de 18/12/2000, Seção 1, p. 30.

evidentemente um dos mais importantes. Porque, é óbvio, ela sozinha jamais teria (terá), como desincumbir-se de tão amplo espectro de tarefas.

Para ficarmos, ainda, no texto constitucional, também é oportuno trazer a exame o art. 205 que, ao tratar "Da Educação", dispõe:

"Art. 205 - A educação, direito e dever do Estado $\underline{\text { e }} \underline{\text { da }}$ família, será promovida e incentivada com a colaboração da sociedade, visando ao pleno desenvolvimento da pessoa, seu preparo para o exercício da cidadania e sua qualificação para o trabalho" (grifos meus)".

Aqui, mais uma vez, evidencia-se o indicativo constitucional de que a educação deve resultar da ação da tríade antes enunciada: Estado, Família e Sociedade.

O art. 206, ao enunciar os princípios norteadores do ensino, logo no inciso I aponta para a "igualdade de condições de acesso e permanência na escola (grifei)".

O art. 208 fala sobre a garantia do "ensino fundamental obrigatório e gratuito" (inciso I), apontando -o como "direito público subjetivo" (art. 208, $\S 1^{\circ}$ ).

Mas o art. 208 não fica só por ai. No $\S 2^{\circ}$ lembra que o "não oferecimento do ensino obrigatório pelo Poder Público, ou sua oferta irregular, importa responsabilidade da autoridade competente". E, no mesmo artigo, o $\S 3^{\circ}$ acrescenta: "Compete ao Poder Público recensear os educandos no ensino fundamental, fazer-lhes a chamada e zelar, junto aos pais ou responsáveis, pela freqüência à escola".

Verifica-se, assim, que a Constituição Federal aponta nitidamente para a obrigatoriedade da presença do aluno na escola, em especial na faixa de escolarização obrigatória ( 7 a 14 anos), instituindo para o Poder Público a obrigação de recensear, fazer a chamada escolar e zelar para que os pais se responsabilizem pela "freqüência à escola".

Já foi visto que à União cabe legislar sobre "diretrizes e bases da educação nacional (C.F. art. 22, XXVI). Isto posto, trata-se de verificar como a Lei $\mathrm{n}^{\circ}$ 9.394/96 (LDBEN), regulamenta os dispositivos constitucionais ora trazidos à colação.

Logo em seu art. $1^{\circ}$ define a educação como abrangente de "processos formativos que se desenvolvem na vida familiar, na convivência humana, no trabalho, nas instituições de ensino e pesquisa, nos movimentos sociais e organizações da sociedade civil e nas manifestações culturais". Para lembrar, $\log 0$ no $\S 1^{\circ}$, que a "Lei disciplina a educação escolar, que se desenvolve predominantemente, por meio do ensino, em instituições próprias (todos os grifos meus)".

Portanto, família, sociedade, organizações culturais e outras, são todas cooperadoras no desenvolvimento de uma educação plena, visando à plena cidadania. Mas a escola é 


\section{PARECER CNE/CEB 34/2000 - HOMOLOGADO}

Despacho do Ministro em 15/12/2000, publicado no Diário Oficial da União de 18/12/2000, Seção 1, p. 30.

agência indispensável, na conjugação dos deveres "da família e do Estado", conforme o art. $2^{\circ}$ da LDB. Não da família sem o Estado ou do Estado sem a família, com inspiração "nos princípios de liberdade e nos ideais de solidariedade humana", tendo "por finalidade o pleno desenvolvimento do educando, seu preparo para o exercício da cidadania e sua qualificação para o trabalho". Certamente, foi sábio o legislador, ao envolver a tríade mencionada na consecução de objetivos tão amplos. Porque a família, ela só, jamais reunirá as condições mínimas necessárias para alcançar objetivos tão amplos e complexos.

Os artigos $3^{\circ}$ e $4^{\circ}$ repetem a Constituição. $\mathrm{O}$ art. $5^{\circ}$ desenvolve, de forma um pouco mais pormenorizada, outro dispositivo da Carta Magna, acrescentando a obrigatoriedade do rito sumário para a queixa na hipótese de descumprimento do $\S 2^{\circ}$ do art. 208 da C.F. O $\S$ $5^{\circ}$ do mesmo artigo fala na possibilidade da criação de formas alternativas de acesso criadas pelo Poder Público, quando for necessário "garantir o cumprimento da obrigatoriedade" de que fala a Lei.

E o art. $6^{\circ}$ é definitivo:

"Art. $6^{\circ}$ - É dever dos pais ou responsáveis efetuar a matrícula dos menores, a partir dos sete anos de idade, no ensino fundamental (todos os grifos meus)".

Relacionado com o art. $6^{\circ}$, o art. 12, inciso VII inclui entre as incumbências dos estabelecimentos de ensino, onde, na faixa de 7 a 14 anos todas as crianças deverão estar matriculadas, que estes deverão "informar os pais e responsáveis sobre a freqüência e o rendimento dos alunos".

Poder-se-ia invocar o art. 24, inciso II, alínea "c", ad argumentandum. Efetivamente, ali está disposto que "independentemente de escolarização anterior mediante avaliação feita pela escola, que defina o grau de desenvolvimento e experiência do candidato e permita sua inscrição na série ou etapa adequada, conforme regulamentação do respectivo sistema", o aluno poderá ser classificado em qualquer série, nos níveis fundamental e médio. Não se trata, obviamente, de um estímulo à desescolarização do ensino. O dispositivo é sábio, visando à viabilização de inserção de alunos desgarrados do processo regular, a qualquer tempo.

Principalmente, em se tratando do ensino fundamental, que é o caso considerado, além dos dispositivos legais enunciados, dos quais o art. $6^{\circ}$ é emblemático, outro merece especial atenção. Trata-se do que se contém no art. 32. O caput, voltando a afirmar que o "ensino fundamental, com duração mínima de oito anos", é obrigatório ( e gratuito na escola pública), enuncia, em seus quatro incisos, os objetivos do ensino fundamental. $\mathrm{O}$ último deles, ao mesmo tempo que fala no "fortalecimento dos vínculos da família", acrescenta também os laços de solidariedade humana e de tolerância recíproca em que se assenta à vida social". 
PARECER CNE/CEB 34/2000 - HOMOLOGADO

Despacho do Ministro em 15/12/2000, publicado no Diário Oficial da União de 18/12/2000, Seção 1, p. 30.

Ora, se o fortalecimento dos vínculos da família é de capital significado, não menos importantes são a solidariedade humana, a tolerância recíproca que fundamentam a vida social. E estes, não deverão ser cultivados no estreito (no sentido de limitado) espaço familiar. A experiência do coexistir no meio de outras pessoas, a oportunidade do convívio com os demais semelhantes, tudo são situações educativas que só a família não proporciona e que, portanto, não garante o que a lei chama de preparo para a "cidadania plena".

$\mathrm{O} \S 4^{\circ}$ do mesmo art. 32 também é bastante elucidador:

"O ensino fundamental será presencial, sendo o ensino a distância utilizado como complementação da aprendizagem ou em situações emergenciais (grifei)".

Este dispositivo, conjugado com o do art. 24, inciso V, que fala do controle da freqüência, pela escola, e da necessidade de uma "freqüência mínima de setenta e cinco por cento do total das horas letivas para aprovação", dá bem a dimensão da importância que o legislador atribuiu ao convívio dos alunos, no ensino fundamental, como parte indispensável do processo educativo da criança e do adolescente. Não se trata apenas de aprender - e até de aprender muito bem - "a língua portuguesa, a matemática, o conhecimento do mundo físico e natural e da realidade social e política, especialmente do Brasil", além da arte, da educação física, de língua estrangeira e de outros conteúdos que venham a ser incluídos em uma parte diversificada.

Ao determinar que o ensino fundamental é presencial, na escola, é claro, e que nele se exige um mínimo de $75 \%$ de freqüência, a lei enfatizou a importância da troca de experiências, do exercício da tolerância recíproca, não sob o controle dos pais mas no convívio das salas de aula, dos corredores escolares, dos espaços de recreio, nas excursões em grupo fora da escola, na organização de atividades esportivas, literárias ou de sociabilidade, que demandam mais que os irmãos apenas, para que reproduzam a sociedade, onde a cidadania será exercida. Porque o preparo para esse exercício é uma das três finalidades fundamentais da educação. As outras sendo o pleno desenvolvimento do educando e sua qualificação para o trabalho (art. $2^{\circ}$, LDBEN).

A possibilidade que a norma legal abre para o ensino fundamental em situação mais flexível, digamos, é a contida sob o título da "Educação de Jovens e Adultos". Mas esta é destinada "àqueles que não tiveram acesso ou continuidade de estudos no ensino fundamental e médio na idade própria". E, neste caso a exigência, quanto ao ensino fundamental, é que os alunos só possam concluí-lo sendo "maiores de quinze anos" (art.37 e 38). 


\section{PARECER CNE/CEB 34/2000 - HOMOLOGADO}

Despacho do Ministro em 15/12/2000, publicado no Diário Oficial da União de 18/12/2000, Seção 1, p. 30.

Finalmente, ainda cabe lembrar que o art. $87, \S 3^{\circ}$ da Lei $n^{\circ} 9.394 / 96$ impõe ao Município e, supletivamente, ao Estado e à União: "matricular todos os educandos a partir de sete anos de idade e, facultativamente, a partir de seis anos, no ensino fundamental (grifei)".

Como argumento, em favor da possibilidade pleiteada, poder-se-ia invocar o art. 81 da mesma lei:

"Art. 81 - É permitida a organização de cursos ou instituições de ensino experimentais, obedecidas as disposições desta Lei (grifei)".

Cautelosamente, para evitar a proliferação de "cursos ou instituições experimentais" que não atendessem ao espírito da permissão, o legislador encerrou o artigo com o intencional "obedecidas as disposições desta lei". Em suma, vale dizer: com um mínimo de 800 horas anuais, distribuídas em um mínimo de 200 dias letivos; com freqüência mínima de $75 \%$ nos cursos presenciais ( no ensino fundamental, é o caso); com um mínimo de 4 horas diárias de trabalho efetivo em sala de aula (art. 34, caput), entre outras disposições que a LDB determina.

Salvo melhor juízo, não encontro na Lei n 9.394, de 20 de dezembro de 1996, Lei de Diretrizes e Bases da Educação Nacional, nem na Constituição da República Federativa do Brasil, abertura para que se permita a uma família não cumprir a exigência da matrícula obrigatória na escola de ensino fundamental. "Matricular" em escola, pública ou privada, para o exclusivo fim de "avaliação do aprendizado" não tem amparo legal, in casu do art. 24, inciso II, alínea "c" visa à avaliação, "pela escola, que defina o grau de desenvolvimento e experiência do candidato", para "sua inscrição na série ou etapa adequada, conforme regulamentação do respectivo sistema (grifei)".

Quanto à orientação da Lei, no que tange à verificação do rendimento escolar, o que a alínea "a", do inciso V, do art. 24 impõe é que "a avaliação seja contínua e cumulativa do_desempenho do aluno, com prevalência dos aspectos qualitativos sobre os quantitativos e dos resultados ao longo do período (letivo) sobre os de eventuais provas finais (grifei)".

Sem esquecer que cabe a cada instituição de ensino expedir históricos escolares, declarações de conclusão de série e diplomas ou certificados de conclusão de cursos somente aos seus alunos, ou seja, àqueles que nela estiveram regularmente matriculados (Art. 24, inciso VII).

Bem compreendo o anseio dos pais autores do pleito endereçado ao Conselho Estadual de Educação de Goiás, quanto julgam "que chegou a hora de buscar o reconhecimento estatal dessa modalidade de educação", a da educação exclusivamente no 
PARECER CNE/CEB 34/2000 - HOMOLOGADO

Despacho do Ministro em 15/12/2000, publicado no Diário Oficial da União de 18/12/2000, Seção 1, p. 30.

dispositivos legais enunciados neste parecer, não vejo como o procedimento possa ser autorizado. Sua adoção dependeria de manifestação do legislador, que viesse a abrir a possibilidade, segundo normas reguladoras específicas.

Por enquanto, na etapa a que se refere o pleito, a matrícula escolar é obrigatória, o ensino é presencial e o convívio com outros alunos de idade semelhante é considerado componente indispensável a todo processo educacional.

\section{II - VOTO DO RELATOR}

À vista do exposto, voto por que a Câmara de Educação Básica do Conselho Nacional de Educação se manifeste sobre o pleito do casal Carlos Alberto Carvalho de Vilhena Coelho e Márcia Marques de Oliveira de Vilhena Coelho nos termos deste parecer, no sentido de que os filhos sejam classificados e matriculados em escola devidamente autorizada nos termos do art. 24 , inciso II, alínea "c" da LDB.

Brasília, DF, 04 de dezembro de 2000.

Conselheiro Ulysses de Oliveira Panisset - Relator

\section{III - DECISÃO DA CÂMARA}

A Câmara de Educação Básica aprova por maioria o voto do relator, com abstenção dos conselheiros Carlos Roberto Jamil Cury e Nelio Marco Vincenzo Bizzo.

Sala das Sessões, em 04 de dezembro de 2000

Conselheiro Francisco Aparecido Cordão - Presidente

Conselheira Raquel Figueiredo Alessandri Teixeira - Vice-Presidente 